\title{
Effectiveness of Schema Therapy in Psychological Distress, Body Image, and Eating Disorder Beliefs in Patients with Anorexia Nervosa
}

\author{
Samira Ansari ${ }^{1}$, Parviz Asgari*(D), Behnam Makvandi ${ }^{(\mathbb{D}}$, Alireza Heidari ${ }^{3}\left(\mathbb{D}\right.$, Naser Seraj Khorrami $^{4}(\mathbb{D})$ \\ 1 Department of Health Psychology, Khorramshahr-Persian Gulf International Branch, Islamic Azad University, \\ Khorramshahr, Iran \\ 2 Associate Professor, Department of Psychology, Ahvaz Branch, Islamic Azad University, Ahvaz, Iran \\ 3 Assistant Professor, Department of Psychology, Ahvaz Branch, Islamic Azad University, Ahvaz, Iran \\ ${ }^{4}$ Assistant Professor, Department of Psychology, Dezful Branch, Islamic Azad University, Dezful, Iran
}

*Corresponding author: Parviz Asgari, Department of Psychology, Ahvaz Branch, Islamic Azad University, Ahvaz, Iran Tel: +989161116182 Email: p.askary@iauahvaz.ac

Received: 31 Mar. 2020 Accepted: 16 May. 2020 ePublished: 01 Aug. 2020

\begin{abstract}
Background and Objective: Due to the role of recognition in eating disorders, the identification of core beliefs and cognitive schemas becomes debatable. This study aimed to determine the effectiveness of schema therapy in psychological distress, body image, and eating disorder beliefs in anorexic patients.

Materials and Methods: This was an applied quasi-experimental study with a pretest and posttest design and control group. The statistical population of the study included patients with an eating disorder, attending the psychological, clinical psychiatric, and obesity treatment centers in Ahvaz, Iran, within the age range of 16-23 years in 2019. The subjects were selected using the purposive sampling method. In this study, the pretest (i.e., filling out the Eating Disorder Beliefs Questionnaire [EDBQ]) was performed before the schema therapy intervention. Then, the intervention was conducted on the experimental group; however, no intervention was carried out for the control group. After the termination of the treatment sessions (12 sessions of $45 \mathrm{~min}$ ), the posttest was performed. Finally, 3 months following the termination of the treatment, the follow-up test was conducted. The data were obtained using the EDBQ, Psychological Distress Questionnaire, and Body Image Concern Inventory. The data were analyzed using multivariate analysis of covariance and SPSS software (version 22).

Results: The results of the present study showed that schema therapy led to a decrease in psychological distress $(\mathrm{F}=157.36, \mathrm{P}<0.0001, \mathrm{Eta}=0.89)$, body image concern $(\mathrm{F}=8.03, \mathrm{P}<0.001$, $\mathrm{Eta}=0.29)$, and eating disorder beliefs $(\mathrm{F}=13.85, \mathrm{P}<0.0001, \mathrm{Eta}=0.91)$.

Conclusion: It can be concluded that schema therapy reduces psychological distress, body image concerns, and eating disorder beliefs.

Keywords: Anorexia nervosa, Body image, Feeding and eating disorders, Psychological distress
\end{abstract}

\section{Background}

The eating disorders are among chronic mental illnesses with lifetime prevalence. Among women, about $2 \%$ of the global population are afflicted with Anorexia nervosa, and approximately $3 \%$ of the afflicted subjects suffer from Bulimia [1]. According to the evidence, the increased prevalence of Anorexia nervosa and Bulimia nervosa [2] are associated with an increased risk of psychopathology, medical problems, and early mortality [3]. There have been factors, such as biological [4] and social [5] factors, personality traits and disorders [6], cognitive schema and core beliefs [7], and family dynamism variables [8] which can be among predisposing factors for anorexia nervosa.

Several factors are involved in Anorexia nervosa among which there are body image and type of the individual's perception of his/her body [9]. Many women and girls suffer from some problems with their body image. The negative body image can cause dissatisfaction with the body and unattractive feeling and ultimately obsession with the physical appearance of a part of the body leading to dysfunction. The misinterpretation of body image can cause physical and psychological problems for an individual [10].

Dissatisfaction with body image is a good symptom of the likelihood of an eating disorder in the long run. Body image dissatisfaction is one of the essential prerequisites for eating disorders. The individuals with negative mental images and misinterpretations are most likely to be afflicted with an eating disorder; they mostly suffer from 
feelings, such as depression, loneliness, low selfesteem, and obsession with weight loss [11]. The results of studies have shown that there is a high level of vulnerability among women with body image dissatisfaction [12].

Psychological distress is one of the effective variables of anorexia. Psychological distress consists of the unpleasant states of the mind, namely depression, anxiety, and stress, all of which include emotional and physiological symptoms [13]. The results of studies have demonstrated that the individuals suffering from higher psychological distress exhibit avoidance behaviors under stressful conditions or do not express their feelings and continue their avoidance behaviors in the form of physiological experiences, thoughts, and memories to quickly reduce their distress [14]. In a study carried out by Winefield et al. [15], it was observed that psychological distress as an emotional disturbance might affect individual's social performance and daily life.

The theory of eating disorder schema therapy emphasizes the roles of core beliefs and schemas in the development and continuation of eating disorders. The beliefs developing from early or later experiences in life may exist in different aspects. However, beliefs that are related to the self are often assumed to play a decisive role in psychopathology [16]. Waller, Dixon, and Ohanian [17] also used the concept of core beliefs to reveal the pathologic center of the anorexia cognition. Generally, it was assumed that early incompatible beliefs are related to impaired independence and performance, causing a cognitive vulnerability in parent-child relationships, which in turn, increases the perception of nutritional problems in having inappropriate relationships and reinforcing incompatible primary beliefs [18].

According to this model, the schemas develop during childhood. They are used as templates to process later experiences, reflecting upon maladaptive schemas often leading to the creation of the unconditional beliefs of the individual about himself/herself [19]. The results of studies have shown that schema therapy $[20,21]$ plays a significant role in the reduction of the beliefs and symptoms of eating disorders [22]. In addition, the findings of other studies have confirmed the effectiveness of schema-focused therapy in the reduction of the symptoms of eating disorders [23]. In schema therapy, the main focus is on the relationship between eating behaviors and schemas; accordingly, the patients gain more conscious awareness and control over the origins and coping practices associated with the symptoms of the eating disorder [24]. Due to the importance of cognition in eating disorders, the identification of core beliefs and cognitive schemas is debatable.

\section{Objectives}

The present study aimed to determine the effectiveness of schema therapy in psychological distress, body image, and eating disorder beliefs in anorexic patients.

\section{Materials and Methods}

This was an applied quasi-experimental study with a pretest and posttest design and control group. The statistical population of the study included patients with an eating disorder, attending the psychological, clinical psychiatric, and obesity treatment centers in Ahvaz, Iran, within the age range of 16-23 years during July to October 2019. The purposive sampling method was employed in this study. The diagnosis of the disorder was established by a psychiatrist based on the fifth edition of the Diagnostic and Statistical Manual of Mental Disorders (DSM-5). In this study, the pretest (i.e., filling out the Eating Disorder Beliefs Questionnaire [EDBQ]) was carried out before the schema therapy intervention. Then, the schema therapy intervention was performed for the experimental group. The control group received no intervention. After the termination of the treatment sessions (12 sessions of $45 \mathrm{~min}$ ), the posttest was conducted. Finally, the follow-up test was performed 3 months following the termination of the treatment.

The first experimental group received the intervention of schema therapy, and the second experimental group received cognitive-behavioral therapy. In addition, the control group received no intervention. The BMI was obtained based on the weight $(\mathrm{kg})$ over height $\left(\mathrm{m}^{2}\right)$. Based on the DSM-5, the patients with Anorexia nervosa in terms of BMI were classified into four groups of mild (BMI>17 $\mathrm{kg} / \mathrm{m}^{2}$ ), median (BMI>16-16.99 $\mathrm{kg} / \mathrm{m}^{2}$ ), severe $\left(\mathrm{BMI}>15-15.99 \mathrm{~kg} / \mathrm{m}^{2}\right)$, and very severe $(\mathrm{BMI}>15$ $\left.\mathrm{kg} / \mathrm{m}^{2}\right)$. In this study, the patients with a BMI of $\geq$ $17 \mathrm{~kg} / \mathrm{m}^{2}$ were enrolled. The first experimental group attended 12 weekly sessions of eating-disorder-based schema therapy. The content of the sessions was set based on the schema-based Group Program for Eating Disorders [25], which were summarily presented in the two following general sections:

\section{Eating Disorder Beliefs Questionnaire}

The EDBQ was developed by Cooper et al. in 1997 as a tool for the self-assessment of eating disorder perceptions and beliefs. The English version of the tool is comprised of 32 items. It includes four subscales of the negative self-beliefs (11 items), weight and shape/figure accepted by others ( 9 
items), weight and shape/figure accepted by the person or self-acceptance (6 items), and overeating control (6 items). The questionnaire items are set for the identification of the individual's stand in each query on a 100-degree scale within 0 (It does not apply to me at all) to 100 (It completely applies to me) [26]. Regarding the concurrent validity, there was a significant correlation between the subscales of the eating disorder beliefs test and eating feedback test $(\mathrm{r}=0.50-0.73)$. A significant correlation was reported between the EDBQ with Beck's Depression Test $(\mathrm{r}=0.39-0.41)$ and Rosenberg selfesteem scale $(\mathrm{r}=0.36-0.71)$ [27].

\section{Psychological Distress Questionnaire}

The questionnaire, which examines the patient's mental status over the past month, was set by Kessler, Barker, Mopp, and Grover et al. in 2003 with 10 items. The items are based on a 5-point Likert scale ( $4=$ Always to $0=$ Never), scored within the range of $0-4$, with a maximum score of 40 . The reliability of the questionnaire was reported to be 0.80 using Cronbach's Alpha coefficient. One example of the items of the questionnaire is, "Have you ever felt tired for the past 4 weeks without any good reason?" [28]. Koochaki et al. observed that the Chronbach's alpha coefficient and retest reliability of the Persian version of this scale were 0.82 and 0.79 , respectively [29].

\section{Body Image Concern Inventory}

This questionnaire was designed in 2005 by Littleton et al. The questionnaire is of a pencilpaper type, including 19 items. The testees should answer the items based on a 5-point Likert scale, with the answers ranging from 1 (Never) to 5 (Always). The validity (coefficient) of the questionnaire was reported by consistent calculation of the 19-items scale of body image using the selfreport scale of physical impairment to be 0.83 [30]. Moreover, in Iran, the reliability values of the body image questionnaire using Cronbach's alpha coefficient were reported to be $0.93,0.95$, and 0.95 , for male students, female students, and total number of students, respectively (Table 1) [31]. Multivariate analysis of covariance was used for inferential analysis. The SPSS software (version 22) was utilized to analyze the data.

Table 1. A summary of schema therapy for patients with an eating disorder

\begin{tabular}{|c|c|c|c|}
\hline Session & Objective & Determining agenda & Teaching technique and designing tasks \\
\hline $1-3$ & $\begin{array}{c}\text { Establishment of a therapeutic relationship, } \\
\text { assessment of the patient's problem, evaluation } \\
\text { of the schemas, and formulation of the problem } \\
\text { based on the procedure of the schema }\end{array}$ & $\begin{array}{l}\text { Explaining schema therapy } \\
\text { model and objectives } \\
\text { transparently and in simple } \\
\text { words to the patients }\end{array}$ & $\begin{array}{l}\text { Summarizing all the information obtained } \\
\text { from schema therapy in the patient's } \\
\text { problem conceptualization form }\end{array}$ \\
\hline $4-6$ & $\begin{array}{l}\text { Identification of the schemas, employment of } \\
\text { cognitive techniques, and challenging the } \\
\text { schemas }\end{array}$ & $\begin{array}{l}\text { Identifying and challenging } \\
\text { the schemas and teaching } \\
\text { the cognitive techniques }\end{array}$ & $\begin{array}{l}\text { Training the cognitive and experimental } \\
\text { techniques }\end{array}$ \\
\hline $7-9$ & $\begin{array}{l}\text { Implementation of emotional (experimental) } \\
\text { techniques }\end{array}$ & $\begin{array}{l}\text { Defining the agenda based } \\
\text { on the subjects and duties }\end{array}$ & $\begin{array}{c}\text { Training the experimental (emotional) } \\
\text { techniques and behavioral pattern- } \\
\text { breaking }\end{array}$ \\
\hline $10-12$ & $\begin{array}{l}\text { Encouragement of the patients to avoid } \\
\text { incompatible contrastive strategies and practice } \\
\text { useful contrastive behaviors }\end{array}$ & $\begin{array}{l}\text { Discussion and debate about } \\
\text { how to avoid incompatible } \\
\text { contrastive behaviors }\end{array}$ & Training the pattern-breaking techniques \\
\hline
\end{tabular}

\section{Results}

Mean (standard deviation) values of the participants' age in the schema therapy groups and control group were reported as 19.53 (2.72) and 20.13 (2.55) years, respectively.

As it can be noticed in Table 2, both of the studied groups are similar in terms of gender and education distributions, because the level of significance exceeds 0.05 .

Multivariate analysis of covariance was employed to examine the significance of the differences in the scores in terms of psychological distress, body image, and eating disorder beliefs in the two schema therapy and control groups. The results of Box's M

Table 2. Frequency distribution and comparison of demographic characteristics of the study participants

\begin{tabular}{|c|c|c|c|c|c|c|}
\hline \multirow{2}{*}{\multicolumn{2}{|c|}{ Demographic variable }} & \multicolumn{2}{|c|}{ Schema therapy } & \multicolumn{2}{|c|}{ Control } & \multirow{2}{*}{ P-value } \\
\hline & & $\mathbf{n}$ & $\%$ & $\mathbf{n}$ & $\%$ & \\
\hline \multirow{2}{*}{ Gender } & Male & 8 & 53.3 & 8 & 53.3 & \multirow[b]{2}{*}{0.37} \\
\hline & Female & 7 & 46.7 & 7 & 46.7 & \\
\hline \multirow{4}{*}{ Education } & Under diploma & 3 & 20 & 2 & 13.3 & \multirow{4}{*}{0.12} \\
\hline & Diploma and Associate' degree & 7 & 46.7 & 4 & 26.7 & \\
\hline & Bachelor's degree & 5 & 33.3 & 5 & 3.3 & \\
\hline & Master's degree & 0 & 0 & 4 & 26.7 & \\
\hline \multirow{2}{*}{ Marital status } & Married & 8 & 53.3 & 4 & 26.7 & \multirow{2}{*}{0.26} \\
\hline & Single & 7 & 46.7 & 11 & 73.3 & \\
\hline
\end{tabular}


Table 3. Mean (SD) of study variables in the experimental and control groups

\begin{tabular}{|c|c|c|c|c|c|c|c|}
\hline \multirow[b]{2}{*}{ Variable } & \multirow[b]{2}{*}{ Group } & \multicolumn{2}{|c|}{ Pretest } & \multicolumn{2}{|c|}{ Posttest } & \multicolumn{2}{|c|}{ Follow-up } \\
\hline & & Mean & $\begin{array}{l}\text { Standard } \\
\text { deviation }\end{array}$ & Mean & $\begin{array}{l}\text { Standard } \\
\text { deviation }\end{array}$ & Mean & $\begin{array}{l}\text { Standard } \\
\text { deviation }\end{array}$ \\
\hline \multirow{2}{*}{ Negative self-belief } & Schema therapy & 54.20 & 5.64 & 43.40 & 5.20 & 42.73 & 5.37 \\
\hline & Control & 54.13 & 5.50 & 53.93 & 5.41 & 53.93 & 5.41 \\
\hline \multirow{2}{*}{$\begin{array}{l}\text { Shape/Figure and weight accepted by } \\
\text { the individual }\end{array}$} & Schema therapy & 50.60 & 6.92 & 43.73 & 6.65 & 42.93 & 6.79 \\
\hline & Control & 44.06 & 5.86 & 43.20 & 5.55 & 44.13 & 5.73 \\
\hline \multirow{2}{*}{$\begin{array}{l}\text { Shape/Figure and weight accepted by } \\
\text { others }\end{array}$} & Schema therapy & 55.53 & 4.92 & 47.26 & 3.41 & 46.60 & 3.45 \\
\hline & Control & 54.20 & 6.51 & 54.06 & 6.30 & 54.06 & 6.30 \\
\hline \multirow{2}{*}{ Overeating control } & Schema therapy & 50.04 & 7.34 & 43.40 & 7.08 & 42.53 & 7.06 \\
\hline & Control & 41.40 & 4.91 & 40.80 & 4.64 & 41.33 & 4.59 \\
\hline \multirow{2}{*}{ Psychological distress } & Schema therapy & 17.46 & 1.35 & 14.40 & 1.50 & 14.93 & 1.62 \\
\hline & Control & 15.40 & 1.45 & 14.60 & 1.12 & 15.13 & 1.40 \\
\hline \multirow{2}{*}{ Body image concerns } & Schema therapy & 48 & 7.04 & 42.13 & 7.55 & 41.40 & 7.57 \\
\hline & Control & 41.46 & 4.29 & 42.13 & 4.54 & 41.60 & 4.50 \\
\hline
\end{tabular}

Table 4. Comparison of pretest and posttest using multivariate analysis of covariance in the experimental and control groups

\begin{tabular}{lccccccc}
\hline Source of effect & Variable & SS & df & MS & F & P & $\mathbf{\eta}^{2}$ \\
\hline \multirow{3}{*}{ Group } & Psychological distress & 564.19 & 2 & 282.09 & 157.76 & 0.0001 & 0.89 \\
& Body Image & 11.25 & 2 & 5.62 & 8.03 & 0.0001 & 0.29 \\
& Eating disorder beliefs & 148.82 & 2 & 74.41 & 13.85 & 0.0001 & 0.91 \\
\hline
\end{tabular}

and Levene's tests were examined before the implementation of variance analysis by repeated measures to observe the pre-assumption. Since Box's $M$ test was not significant for any of the variables (Box's $\mathrm{M}=23.98 ; \mathrm{df}=20 ; \mathrm{P}>0.05$ ), the homogeneity of the variance-covariance matrices was correctly observed. In addition, the nonsignificance of the variables in Levene's test showed that the intergroup equality condition of the variances was observed, and the dependent variable error variance was equal for all the groups. Mean (SD) of research variables are presented in Table 3. The results of Table 4 show that the variables of psychological distress (157.76), body image (8.03), and eating disorder beliefs (13.85) are all statistically significant with the p-values of 0.0001 .

\section{Discussion}

The obtained results of the present study showed that schema therapy was effective in the improvement of psychological distress in anorexic patients, which is in line with the findings of studies carried out by Simpson et al. [32] and Mountford et al. [33]. In order to explain the aforementioned finding, it can be said that according to the literature, it is evident that there is a relationship between the early experiences of childhood and adaptation of early incompatible schemas. The schema therapy takes into account the psychological themes that are characteristic of the patients with cognitive impairment anomalies and terms them as early useless schemas.

Early useless schemas are the pervasive and profound patterns or themes of memories, emotions, and body feelings formed in childhood or youth, continuing in the course of life, are about the relationship with others, are severely useless, and fight for their survival [32]. Although an individual knows that the schema leads to his/her dissatisfaction, she/he feels comfortable with it leading the individual to conclude that his/her schema is correct. The schemas are fixed cognitive structures that are repressed during recovery. The potential structures are reactivated by stressful life events and give access to a network of severelyorganized stored personal information that is mainly undesirable. This problem accelerates the outbreak of the disorder in patients with anorexia. Schema therapy reduces pain, psychological anxiety, and distress that are observed in the life of an individual with anorexia disorder [33].

Based on the studies, it can be concluded that schema therapy training and implementation of cognitive and emotional techniques can modify the early incompatible schemas and improve psychological distress by discharging the emotions and improving the negative feelings. In addition, it can be said that schema therapy helps the therapist to define more chronic and more deep-seated problems in order to organize them in a comprehensible way. By the adoption of this model, individuals can perceive the incompatibility of their early schemas [34]. As a result of acknowledging the presence of early schemas, individuals become more motivated to get rid of the problems. Therefore, based on the results of the present study, schema therapy can improve the psychological distress in patients with anorexia.

The results of the current study showed that schema therapy could improve the body image in patients with anorexia. The finding of the present study are in line with the findings of studies carried 
out by Simpson et al. [32] and Mountford et al. in this regard [33]. In order to explain this finding, it can be said that the patients with anorexia may not be aware of their own negative and positive emotions and display their emotions when they are involved in the stressful situations of life. It is due to the fact that their problems cause them to evaluate themselves negatively in their social situations and become less entangled with social functions, with adverse effects appearing as some problems of self-efficacy. However, schema therapy enables individuals to become aware of their negative emotions and adverse effects. They can attempt to keep their emotional life healthy by the reassessment of emotions in different situations and consequently improvement of their self-efficacy [35].

The present study, similar to other studies, has several limitations, which can be expressed to reinforce the findings and recommendations of the study and enable researchers to take effective measures to eliminate the risk of internal and external validity of the research projects. The main limitation of the present study is the restricted results of the study with patients with anorexia. The study was conducted only on the patients with anorexia in Ahvaz; therefore, caution should be exercised when generalizing the results to other areas and cities. It is recommended to carry out this study once more with another study population and evaluate and compare the results with the findings of the current study. It is suggested to perform this study once more in other cities and assess the results. It is also recommended that this study should be followed by individual counseling after group training.

\section{Conclusions}

It can be concluded that schema therapy reduces psychological distress, body image concerns, and eating disorder beliefs.

\section{Compliance with ethical guidelines}

All the ethical principles were considered in the present study. The participants were informed about the purpose of the study and implementation of the stages. In addition, informed consent was obtained from all the study subjects. The participants were also assured of the confidentiality of their information. Moreover, the subjects were allowed to withdraw from the study at any time, and the results of the study would be available to them if desired. The current study was extracted from a doctoral dissertation in psychology at the Islamic Azad University of Ahvaz and approved by the Ethics Committee of the Islamic Azad University of Ahvaz with the ethics code of IR.IAU.AHVAZ.REC.1398.014.

\section{Acknowledgments}

The authors would like to express their gratitude to the participants, who greatly cooperated with this research project.

\section{Funding/Support}

The current study did not receive any specific grant from funding agencies in public, commercial, or not-for-profit sectors.

Conflicts of Interest

The authors declare that there is no conflict of interest.

\section{References}

1. Agras WS, Lock J, Brandt H, Bryson SW, Dodge E, Halmi $\mathrm{KA}$, et al. Comparison of 2 family therapies for adolescent anorexia nervosa: a randomized parallel trial. JAMA Psychiatry. 2014; 71(11):1279-86. [DOI:10.1001/jamap sychiatry.2014.1025] [PMID] [PMCID]

2. Allan S, Goss K. Eating disorder beliefs and behaviours across eating disorder diagnoses. Eating Behaviors. 2014; 15(1):42-4. [DOI:10.1016/j.eatbeh.2013.10.002] [PMID]

3. Alwerthan TA, Swanson DP, Rogge RD. It's better to give than to receive: psychological need satisfaction mediating links between wasta (favouritism) and individuals psychological distress. International Journal of Psychology. 2018; 53(Suppl 1):11-20. [DOI: 0.1002/ijop.12419] [PMID]

4. American Psychiatric Association. Diagnostic and statistical manual of mental disorders (DSM-5®). New York: American Psychiatric Pub; 2013.

5. Bedford O, Hwang KK. Guilt and shame in Chinese culture: a cross-cultural framework from the perspective of morality and identity. Journal for the Theory of Social Behaviour. 2003; 33(2):127-44. [DOI:10.1111/1468-5914.00210]

6. Birkett M, Newcomb ME, Mustanski B. Does it get better? A longitudinal analysis of psychological distress and victimization in lesbian, gay, bisexual, transgender, and questioning youth. Journal of Adolescent Health. 2015; 56(3):280-5. [DOI:10.1016/j.jadohealth.2014.10.275] [PMID] [PMCID]

7. Caspi A, Amiaz R, Davidson N, Czerniak E, Gur E, Kiryati $\mathrm{N}$, et al. Computerized assessment of body image in anorexia nervosa and bulimia nervosa: comparison with standardized body image assessment tool. Archives of Women's Mental Health. 2017; 20(1):139-47. [DOI:10.1007/s00737-016-0687-4] [PMID]

8. Cicmil N, Eli K. Body image among eating disorder patients with disabilities: a review of published case studies. Body Image. 2014; 11(3):266-74. [DOI:10.1016/j.bodyim.2014. 04.001] [PMID]

9. Cooper MJ, Rose KS, Turner $\mathrm{H}$. Core beliefs and the presence or absence of eating disorder symptoms and depressive symptoms in adolescent girls. International Journal of Eating Disorders. 2005; 38(1):60-4. [DOI:10.1002/ eat.20157] [PMID]

10. de Klerk N, Abma TA, Bamelis LL, Arntz A. Schema therapy for personality disorders: a qualitative study of patients and therapists' perspectives. Behavioural and Cognitive Psychotherapy. 2017; 45(1):31-45. [DOI:10.1017/S1352465 816000357] [PMID]

11. Fairburn CG, Cooper Z, Doll HA, O'Connor ME, Bohn K, Hawker DM, et al. Transdiagnostic cognitive-behavioral therapy for patients with eating disorders: a two-site trial with 60-week follow-up. American Journal of Psychiatry. 2009; 166(3):311-9. [DOI:10.1176/appi.ajp.2008.08040608] [PMID] [PMCID]

12. Fichter MM, Quadflieg N. Mortality in eating disordersresults of a large prospective clinical longitudinal study. International Journal of Eating Disorders. 2016; 49(4):391401. [DOI:10.1002/eat.22501] [PMID]

13. Frostad S, Danielsen YS, Rekkedal GA, Jevne C, Dalle Grave $\mathrm{R}, \mathrm{R} \varnothing \varnothing$, et al. Implementation of enhanced cognitive behaviour therapy (CBT-E) for adults with anorexia nervosa in an outpatient eating-disorder unit at a public hospital. Journal of Eating Disorders. 2018; 6(1):12. [DOI:10.1186/s40337-018-0198-y] [PMID] [PMCID]

14. Griffiths S, Mond JM, Murray SB, Touyz S. Positive beliefs about anorexia nervosa and muscle dysmorphia are associated with eating disorder symptomatology. Australian \& New Zealand Journal of Psychiatry. 2015; 49(9):812-20. 
[DOI:10.1177/0004867415572412] [PMID]

15. Hughes ML, Hamill M, van Gerko K, Lockwood R, Waller G. The relationship between different levels of cognition and behavioural symptoms in the eating disorders. Eating Behaviors. 2006; 7(2):125-33. [DOI:10.1016/j.eatbeh.2005. 09.001]

16. Jenkins PE, Morgan C, Houlihan C. Outpatient CBT for underweight patients with eating disorders: effectiveness within a National Health Service (NHS) eating disorders service. Behavioural and Cognitive Psychotherapy. 2019; 47(2):217-29. [DOI:10.1017/S1352465818000449] [PMID]

17. Junne F, Zipfel S, Wild B, Martus P, Giel K, Resmark G, et al. The relationship of body image with symptoms of depression and anxiety in patients with anorexia nervosa during outpatient psychotherapy: results of the ANTOP study. Psychotherapy. 2016; 53(2):141-51. [DOI:10.1037/ pst0000064] [PMID]

18. Loumidis K, Wells A. Exercising for the wrong reasons: relationships among eating disorder beliefs, dysfunctional exercise beliefs and coping. Clinical Psychology \& Psychotherapy: An International Journal of Theory \& Practice. 2001; 8(6):416-23. [DOI:10.1002/cpp.298]

19. McElroy SL, Hudson JI, Mitchell JE, Wilfley D, FerreiraCornwell MC, Gao J, et al. Efficacy and safety of lisdexamfetamine for treatment of adults with moderate to severe binge-eating disorder: a randomized clinical trial. JAMA Psychiatry. 2015; 72(3):235-46. [DOI:10.1001/jamap sychiatry.2014.2162] [PMID]

20. Mehler PS, Brown C. Anorexia nervosa-medical complications. Journal of Eating Disorders. 2015; 3(1):11. [DOI:10.1186/s40337-015-0040-8] [PMID] [PMCID]

21. Mountford VA, Brown A, Bamford B, Saeidi S, Morgan JF, Lacey $\mathrm{H}$. BodyWise: evaluating a pilot body image group for patients with anorexia nervosa. European Eating Disorders Review. 2015; 23(1):62-7. [DOI:10.1002/erv.2332] [PMID]

22. Murphy CM, Stojek MK, MacKillop J. Interrelationships among impulsive personality traits, food addiction, and body mass index. Appetite. 2014; 73:45-50. [DOI:10.1016/ j.appet.2013.10.008] [PMID] [PMCID]

23. Rodgers RF, Paxton SJ, McLean SA, Massey R, Mond JM, Hay PJ, et al. Stigmatizing attitudes and beliefs toward bulimia nervosa: The importance of knowledge and eating disorder symptoms. The Journal of Nervous and Mental Disease. 2015; 203(4):259-63. [DOI:10.1097/NMD.000000 0000000275] [PMID]

24. Stice E, Presnell K, Spangler D. Risk factors for binge eating onset in adolescent girls: a 2-year prospective investigation. Health Psychology. 2002; 21(2):131-8. [PMID]
25. George L, Thornton C, Touyz SW, Waller G, Beumont PJ. Motivational enhancement and schema-focused cognitive behaviour therapy in the treatment of chronic eating disorders. Clinical Psychologist. 2004; 8(2):81-5. [DOI:10.1080/13284200412331304054]

26. Bradford R, Rutherford D. The eating disorder belief questionnaire: in-patient adolescent scores. Clinical Child Psychology and Psychiatry. 2001; 6(4):513-8. [DOI:10.1177/ 1359104501006004005]

27. Abbaspoor Z, Javadifar N, Miryan M, Abedi P. Psychometric properties of the Iranian version of mindful eating questionnaire in women who seeking weight reduction. Journal of Eating Disorders. 2018; 6(1):33. [DOI:10.1186/ s40337-018-0220-4] [PMID] [PMCID]

28. Slade T, Grove R, Burgess P. Kessler psychological distress scale: normative data from the 2007 Australian National Survey of Mental Health and Wellbeing. Australian and New Zealand Journal of Psychiatry. 2011; 45(4):308-16. [DOI:10.3109/00048674.2010.543653] [PMID]

29. Koochaki GM, Charkazi A, Hasanzadeh A, Saedani M, Qorbani M, Marjani A. Prevalence of stress among Iranian medical students: a questionnaire survey. Eastern Mediterranean Health Journal. 2011; 17(7):593-8. [PMID]

30. Littleton HL, Axsom D, Pury CL. Development of the body image concern inventory. Behaviour Research and Therapy. 2005; 43(2):229-41. [DOI:10.1016/j.brat.2003.12.006] [PMID]

31. Ghadakzadeh S, Ghazipour A, Khajeddin N, Karimian N, Borhani M. Body Image Concern Inventory $(\mathrm{BICl})$ for identifying patients with BDD seeking rhinoplasty: using a Persian (Farsi) version. Aesthetic Plastic Surgery. 2011; 35(6):989-94. [DOI:10.1007/s00266-011-9718-8] [PMID]

32. Mountford V, Waller G. Using imagery in cognitivebehavioral treatment for eating disorders: Tackling the restrictive mode. International Journal of Eating Disorders. 2006; 39(7):533-43. [DOI:10.1002/eat.20329] [PMID]

33. Simpson SG, Morrow E, Reid C. Group schema therapy for eating disorders: a pilot study. Frontiers in Psychology. 2010; 1:182. [DOI:10.3389/fpsyg.2010.00182] [PMID] [PMCID]

34. Watson HJ, Bulik CM. Update on the treatment of anorexia nervosa: review of clinical trials, practice guidelines and emerging interventions. Psychological Medicine. 2013; 43(12): 2477-500. [DOI:10.1017/S0033291712002620] [PMID]

35. Westmoreland P, Krantz MJ, Mehler PS. Medical complications of anorexia nervosa and bulimia. The American Journal of Medicine. 2016; 129(1):30-7. [DOI:10.1016/j.amjmed.2015.06.031] [PMID] 